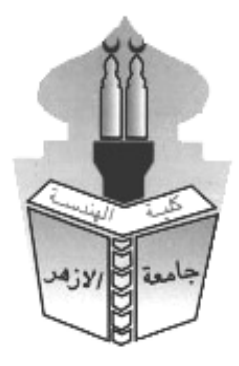

\title{
CLASSIFYING MOSQUES ACCORDING TO THE SYMBOLISM OF THE ARCHITECTURAL ELEMENTS AN ANALYTICAL STUDY OF A BASOUNAH MOSQUE - EGYPT
}

\author{
Hesham Osman Abd Elrahman \\ Department of Architectural Engineering, Faculty of Engineering, Al-Azhr University, \\ Qena, Egypt. \\ E-mail: heshamosman.arch@azhar.edu.eg
}

\begin{abstract}
Mosques have a special historical character and architectural richness that surpasses other architectural works. It is not limited to performing its function as a house of worship only; rather it exceeds it, as it carries within it a record of the history of islamic civilization throughout its ages. In many Muslim-majority countries, the historical picture of mosque architecture has dominated minds. That image is reused in designing the mosque elements. The architectural elements in the mosques were transformed into symbolic elements, so the minaret and the dome became the most prominent formation elements of the mosque architecture and the visual image of the islamic city. Thus, the features of the formative legacy of the mosque's architecture and its expressive elements are associated with fixed frameworks that they do not overlook, which are the original when designing any mosque, Which prompted the expressive formulation of the mosque to be predetermined, linked in the minds of the designer and the user in forms that may not accept change. With the emergence of modern architectural trends at the end of the eighteenth century, as a result of many social, political and economic factors, along with the emergence and development of new materials in construction,

This in turn affected the architecture of mosques and changed the historical mental image and developed it at the urban, formal and technical levels. This problem, which represents a state of contradiction, led to the emergence of modern forms of the architectural vocabulary of the mosque and even their disappearance in other times. Therefore, the research focuses through its theoretical and analytical methodology to analyze theories and opinions about the symbolism and modernity of the original architectural elements in the architectural composition of the mosque without entering into its historical development. Extracting a classification of contemporary mosques according to the symbolism of their architectural elements, This is followed by an analytical study of symbolic elements in one of the contemporary mosque models, through studying the concept of symbolism in architecture and reviewing the modern architectural elements of the mosque through this concept.
\end{abstract}

KEYWORDS: Mosques, Symbolism, Architectural Elements, Minaret, Dome. 


\section{تصنيف المساجد طبقا لرمزية العناصر المعمارية دراسة تحليلية لمسجد باصونة ـ مصر هثام عثمان عبد الرحمن

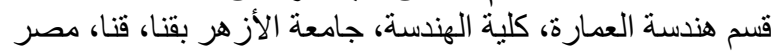 \\ البريد الاليكترونى: E-mail: heshamosman.arch@azhar.edu.eg}

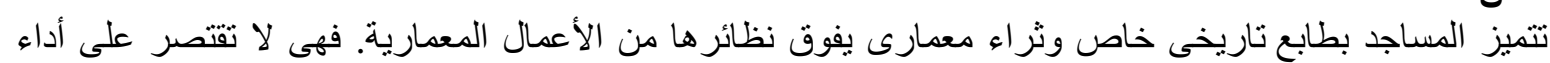

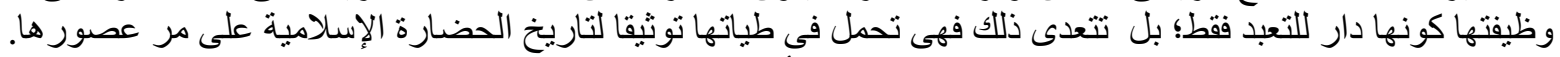

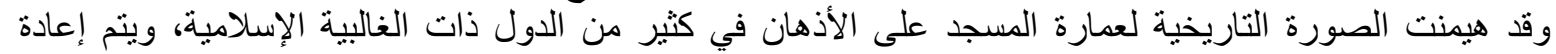

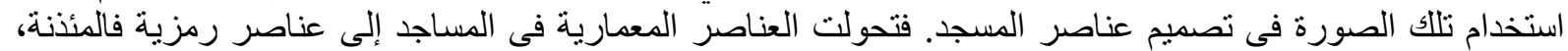

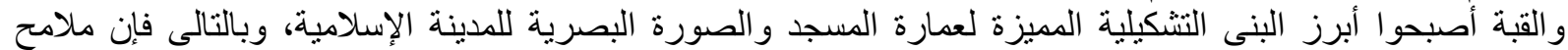

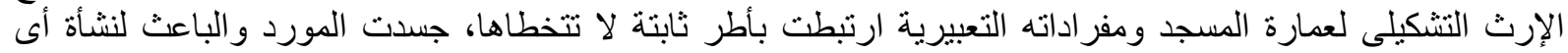

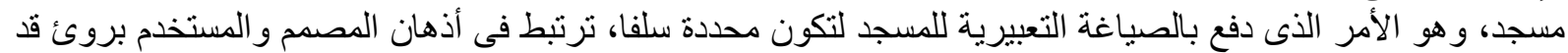
لا تحتمل التغيير.

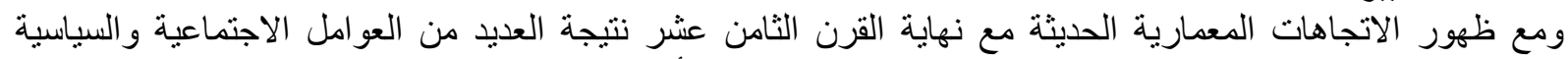

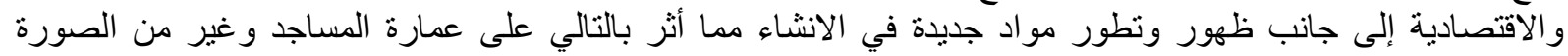

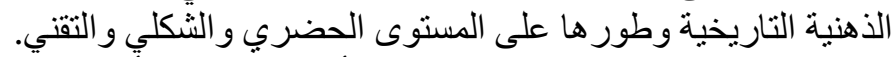

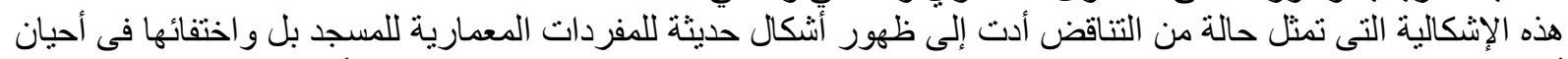

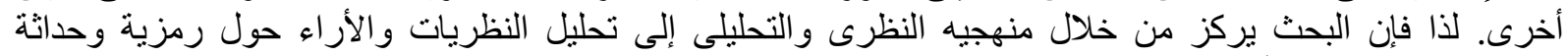

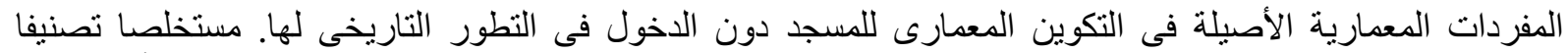

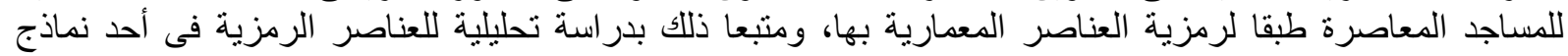

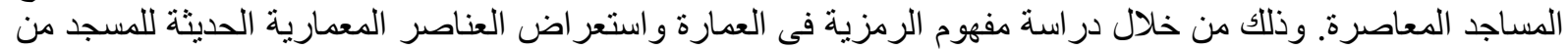

الكلمات المفتاحية: المساجد، الرمزية، العناصر المعمارية، المئذنة، القبة

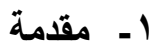

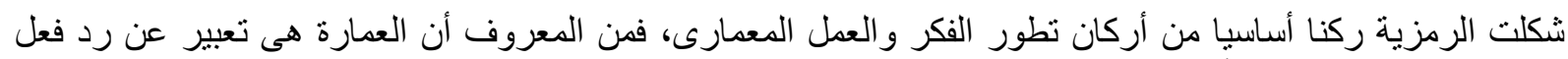

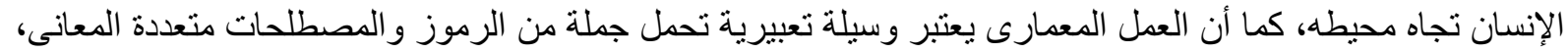

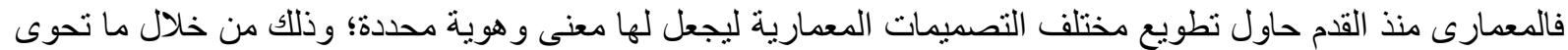
هذه التصميمات من عناصر ومؤشر الفئ ات رمزية.

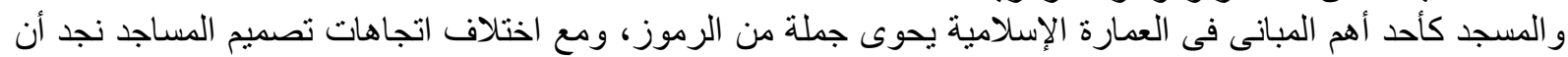

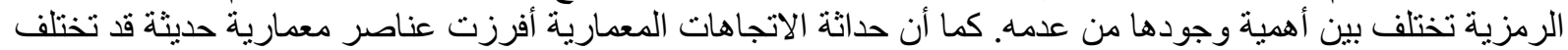

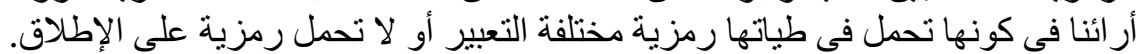

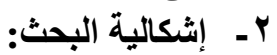

تتمثل المشكلة البحثية فى وجود البهائة حالة من الالتباس بين حتمية وجود العناصر المعمارية الرمزية فى المساجد وبين

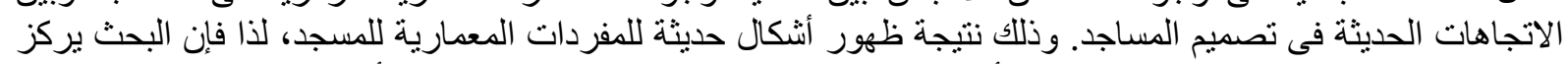

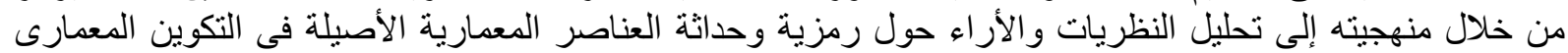

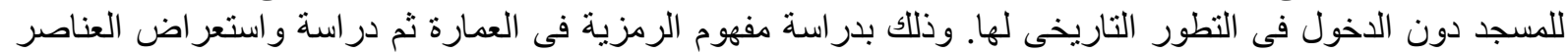

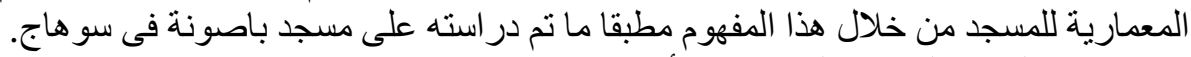
وتعتمد هذه الورقة البحثية على منهجين أساسيين:

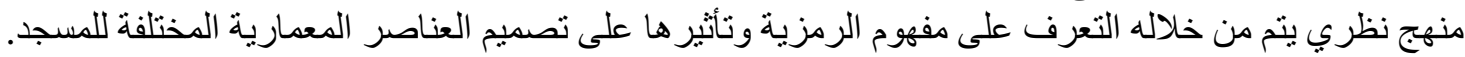

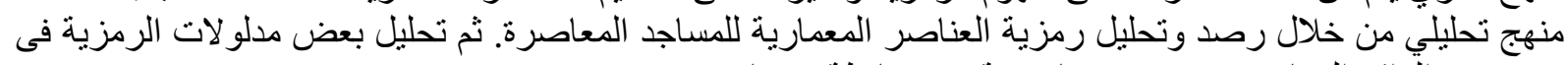

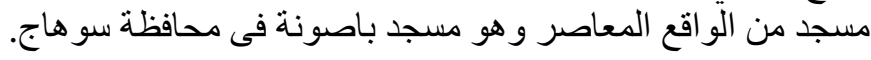

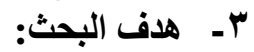

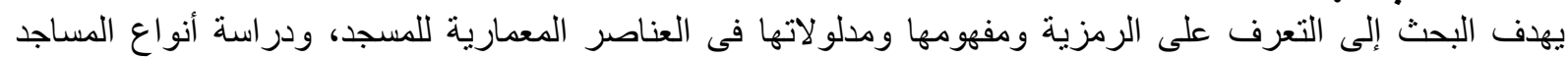

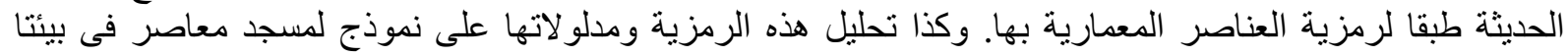
الإقليمية. 
يفترض البحث بأنه يمكن تصنيف الاتجاهات المعمارية لعمارة المساجد من خلال تو اجد عناصره الرمزية المشكلة للصورة

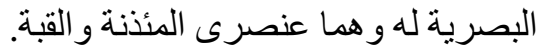

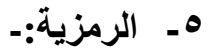

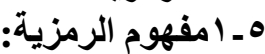

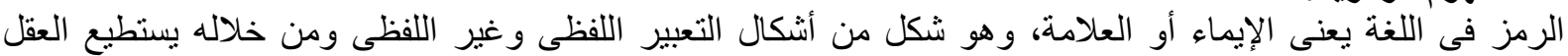

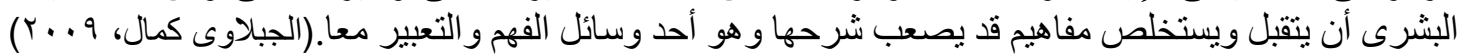

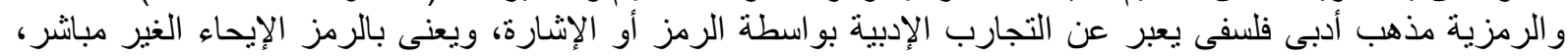

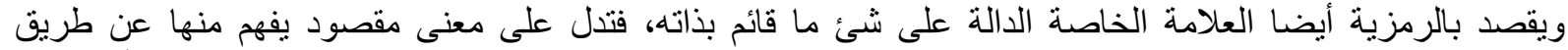

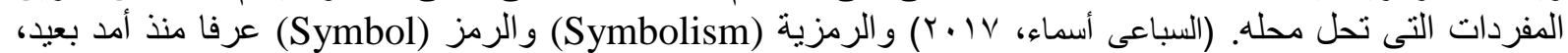

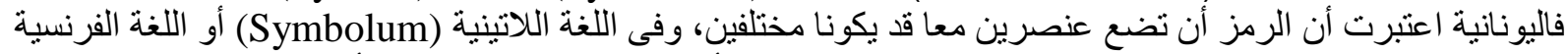

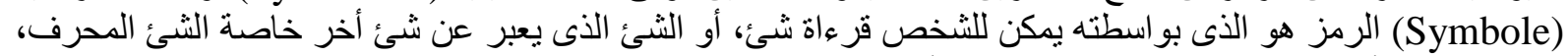

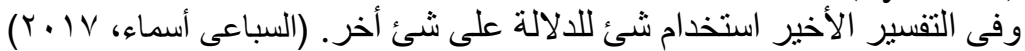

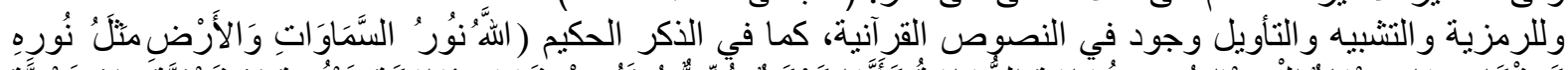

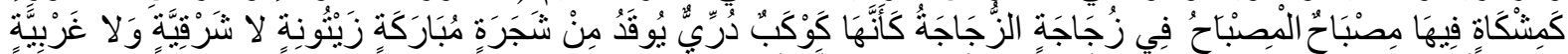

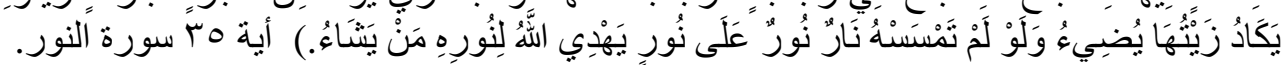

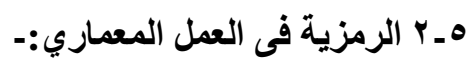

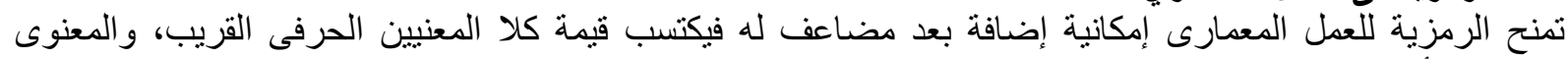

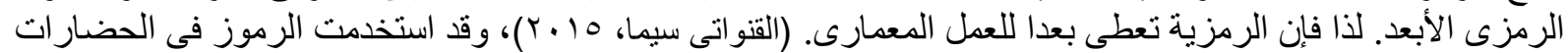

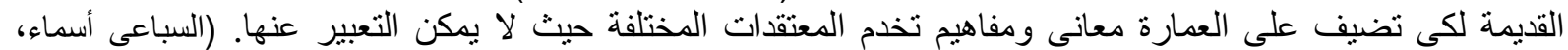

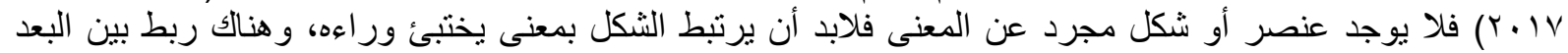

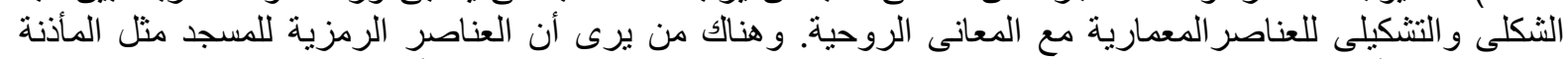

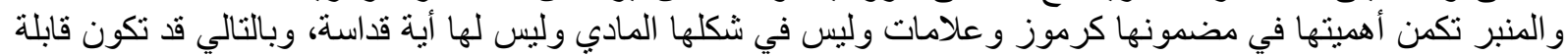

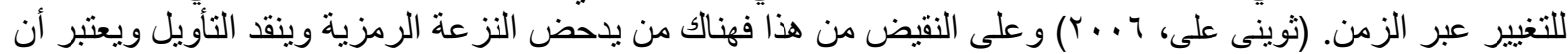

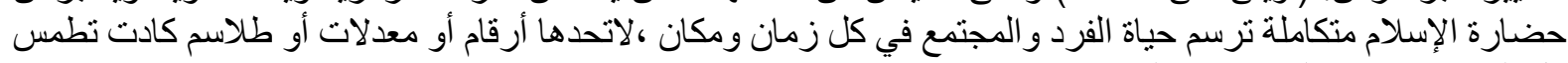

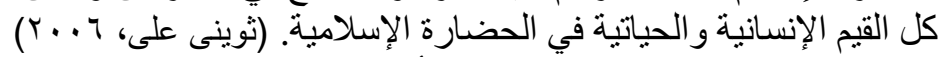

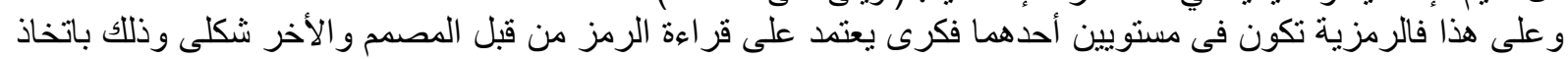

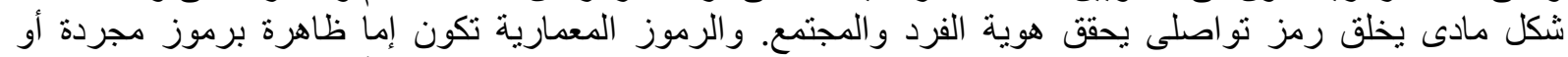

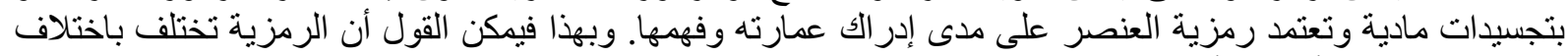

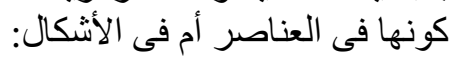

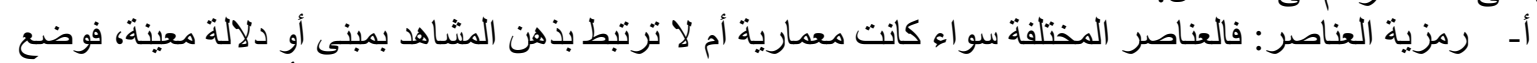

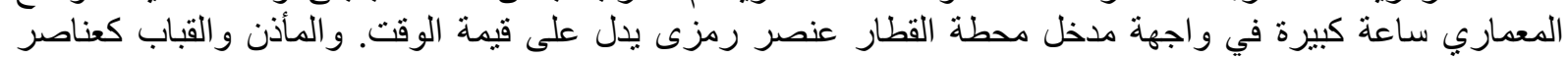

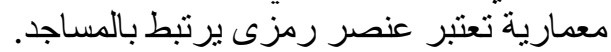

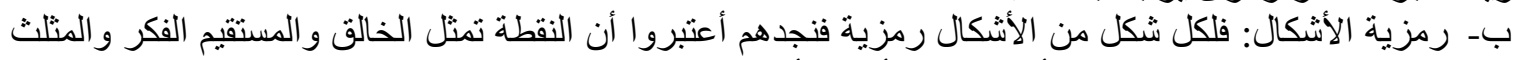

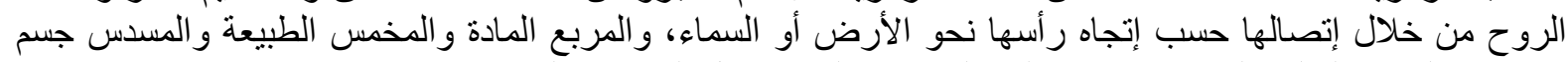

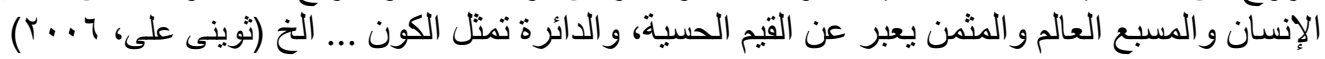

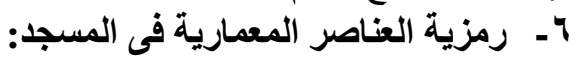
قبل دراسة رمزية عناصر المسجد المعمارية لمدية لابد من التعرف على اتجاهات تصميم المساجد لمعرفة العناصر المعمارية

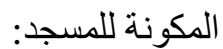

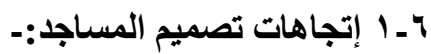
وقد قسمث إتجاهات تصميم المساجد إلى "إتجاه تقليدى محلى، إتجاه محافظ، إتجاه إسلامى محدث، إتجاه تلقيطى، إتجاه إنجاه

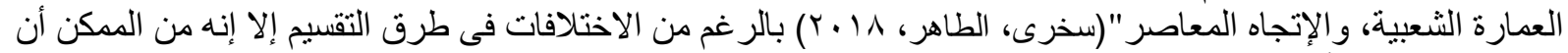

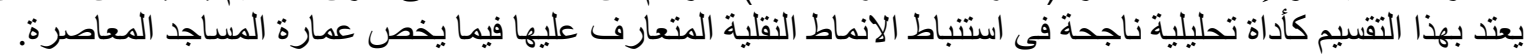

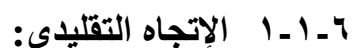

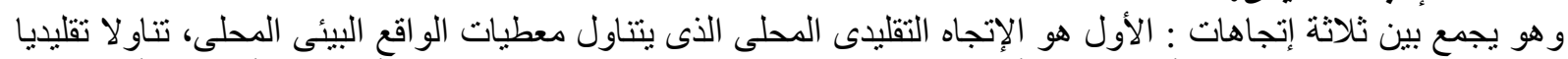

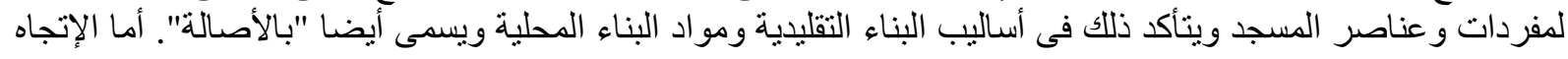


الثانى فهو "الإتجاه الدحافظ "الذى يعمد إلى الحفاظ على مفردات الموروث التر اثى لعمارة المسجد، باستنباط أثنكال مألوفة

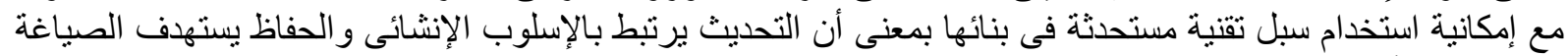

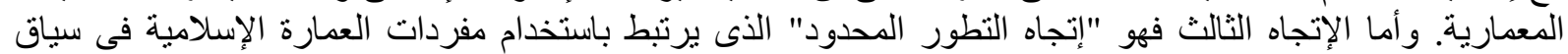
منطور وتقنيات حديثة ويعتمد الارتباط بالنطاق الجغر افى المحلى على استخدام عناصر رمزية بلقية تقليدية.

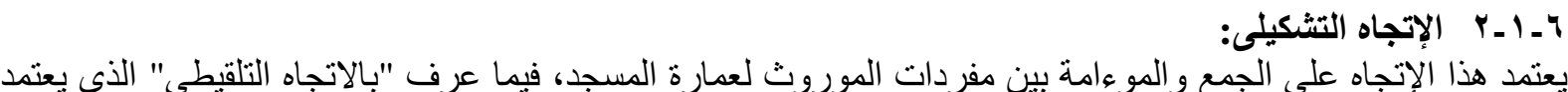

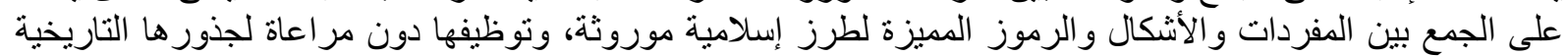
ويطلق عليه أيضا "إتجاه العمارة الثعبية"، فهذا الإتجاه هو نتاج لنقافة العامة ويفتة التهر إلى المرجعية.

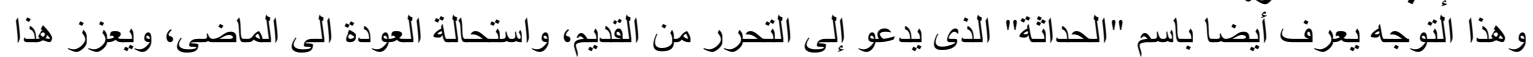

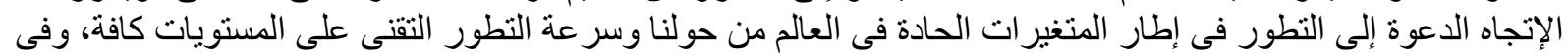

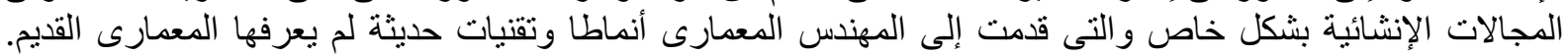

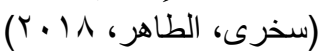

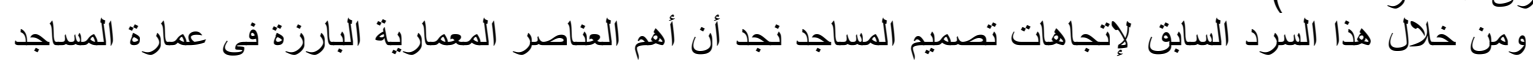

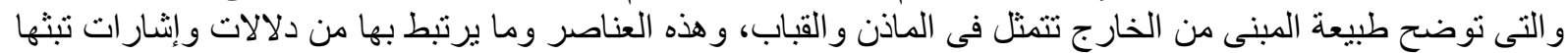
لعقل المشاهد فيقر أ مباشرة طبيعة المبنى نطلق عليها رمزية العناصر المعمارية.

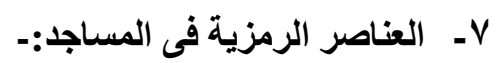

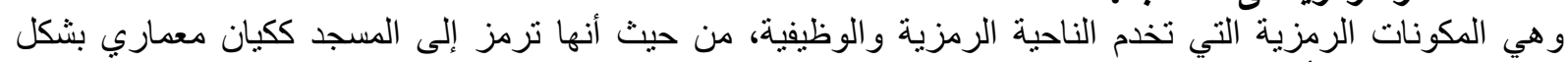

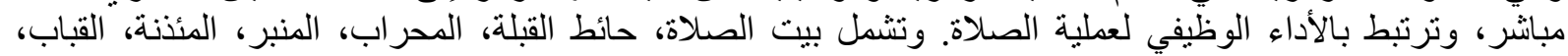

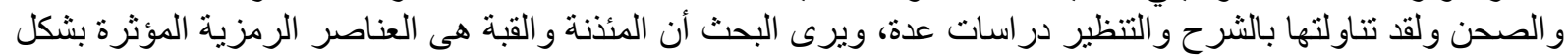

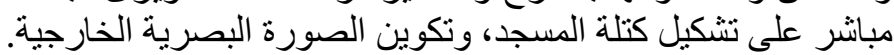

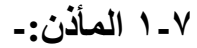

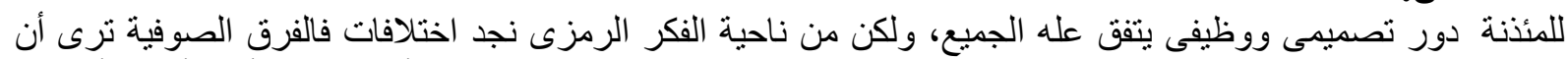

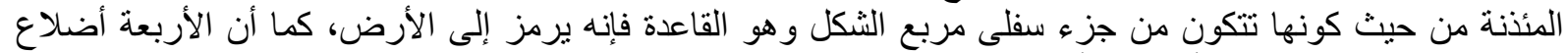

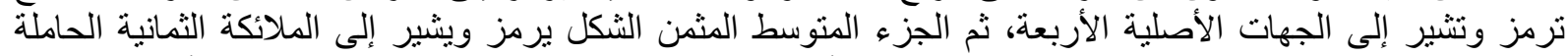

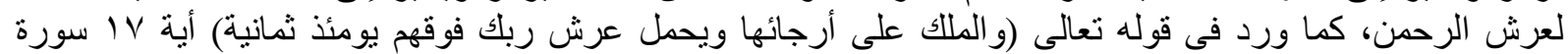

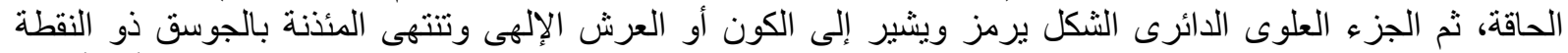

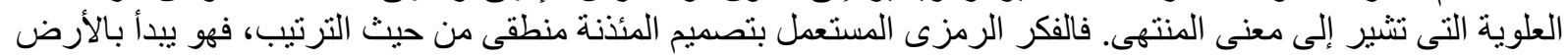

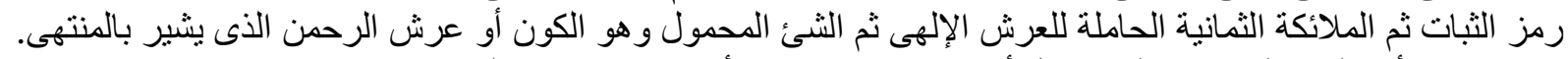

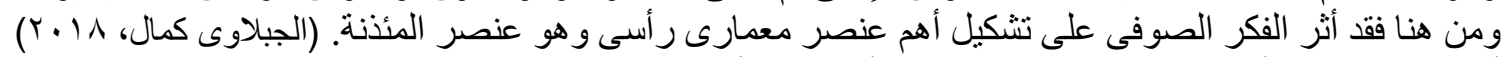

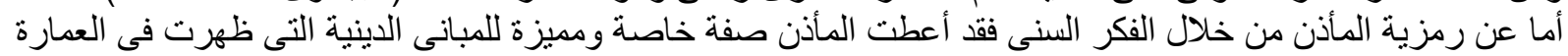

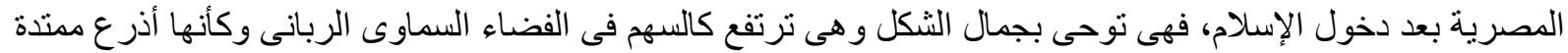

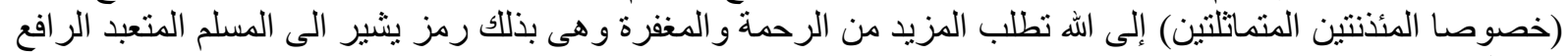
يديه إلى الله. كما أن هناك من يرى أن المئذنتين قد تم تصميمهما بحيث يكونو ا متشابهتين من حيث التصميم المعمارى ويتم وضعهما

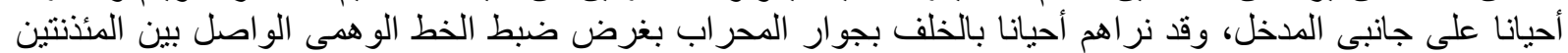

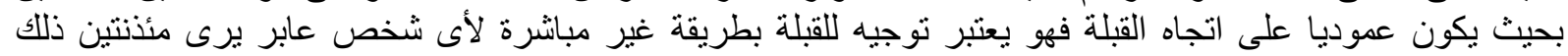

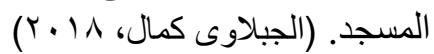

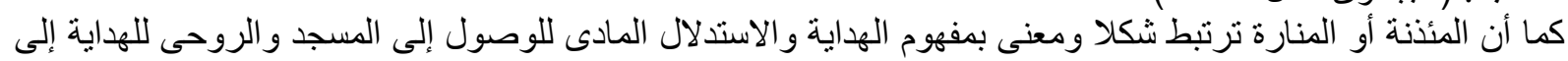

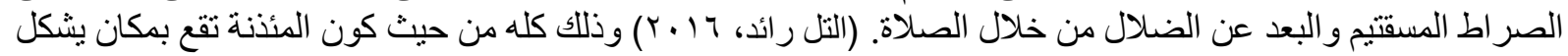

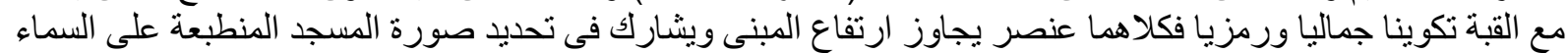

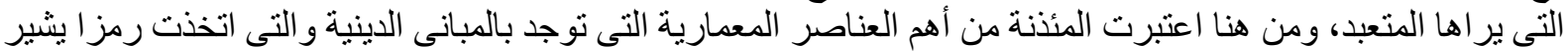

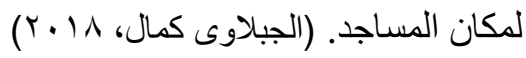




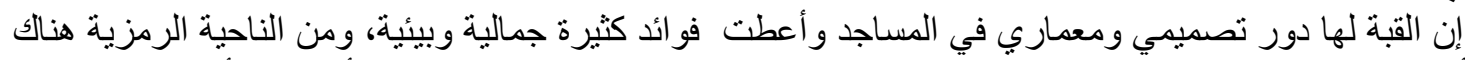

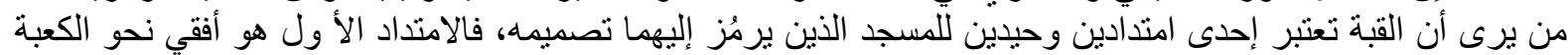

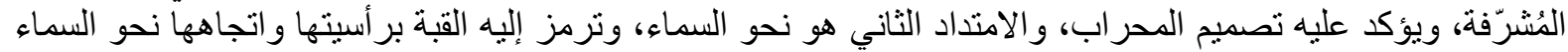

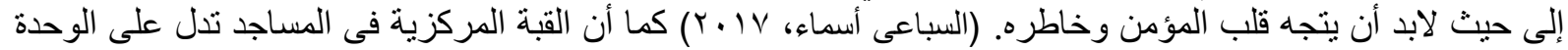

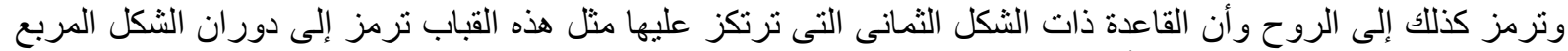

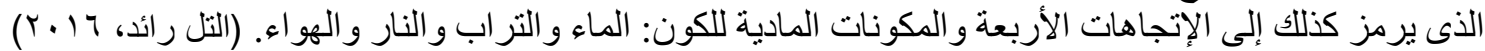

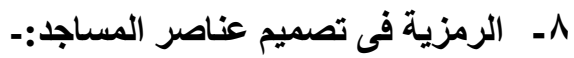

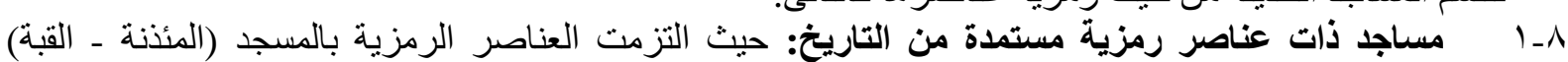

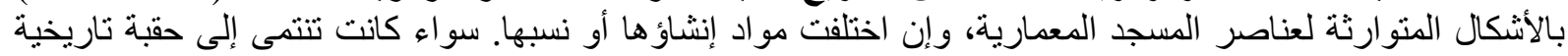

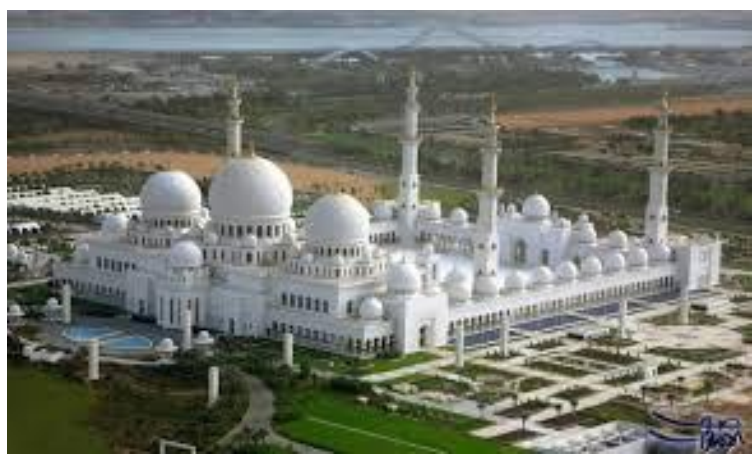

"شكل رقم ץ"مسجد الثيخ زايد - الإمارات

https://abudhabiculture.ae/ar/experience/historiclandmarks/sheikh-zayed-grand-mosque

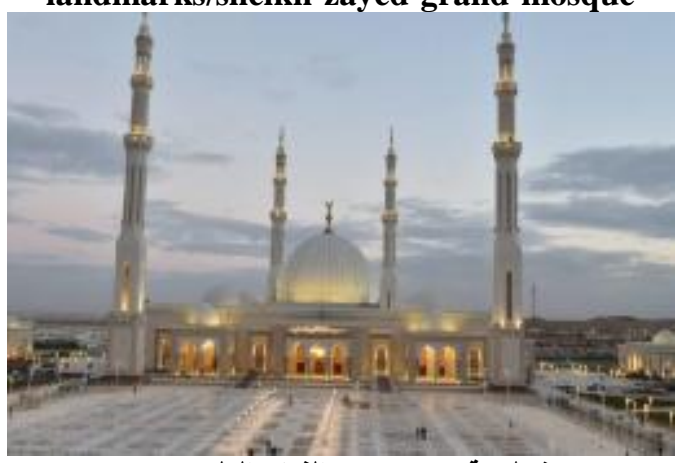

"شكل رقم ؛ " مسجد الفتاح العليم - مصر https://newcapital.info

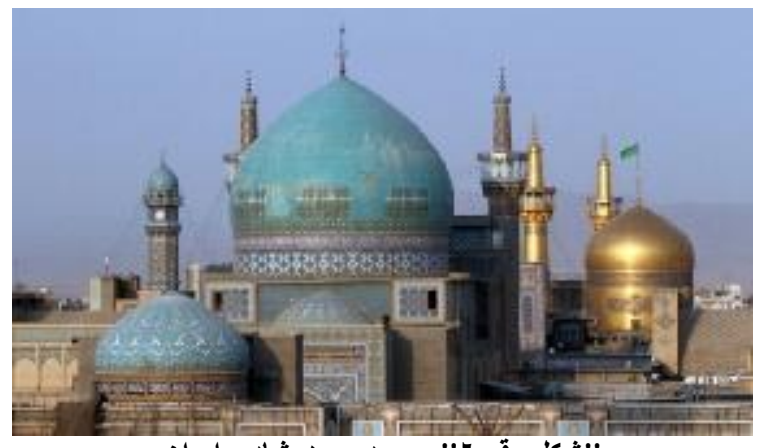

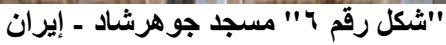

http://arabicradio.net/news/3917

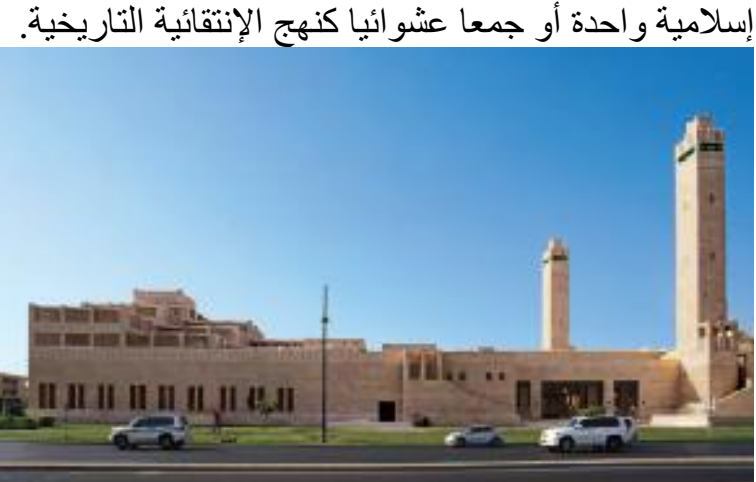

"شكل رقم ا" مسجد الثبخة سلامة ـ الإمارات

https://alfozanaward.org/ar/mosques/alsheikhasalama-ar/

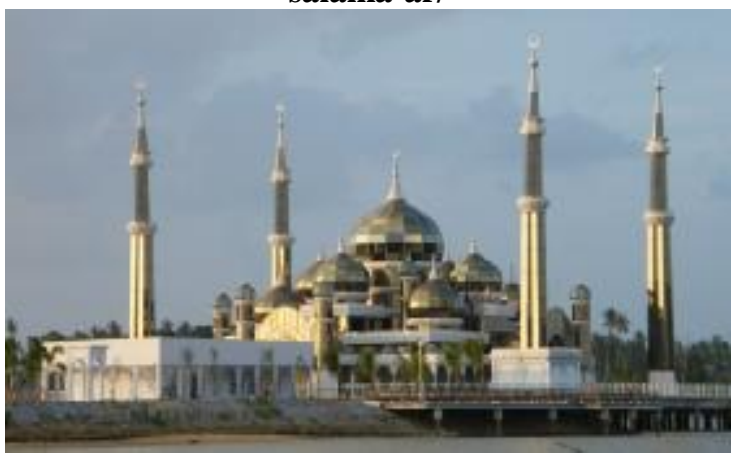

"شكل رقم ب" مسجد الكريستال - ماليزيا

https://commons.wikimedia.org/w/index.php?curid $=\lambda r r 1.79$

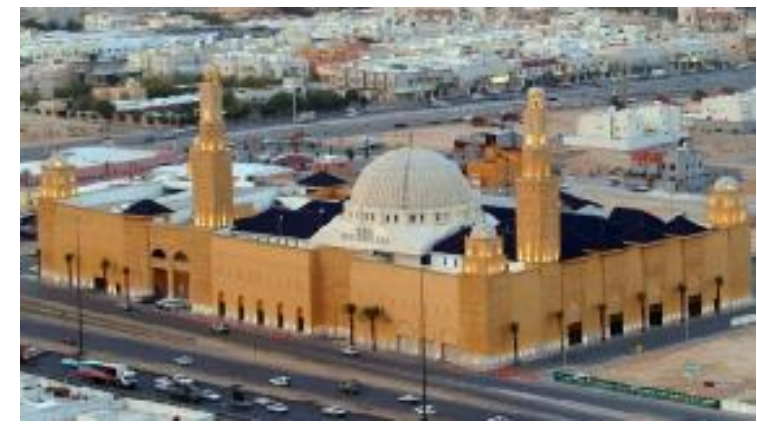

"شكل رقم ه " مسجد الراجحي - الرياض ـ السعودية

h ps://rm.org.sa/ar/branch/90 


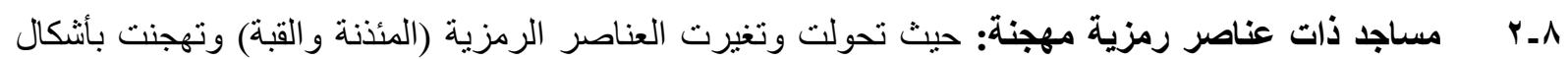

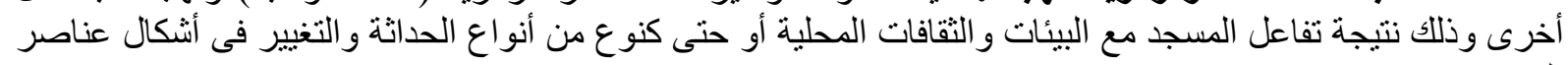

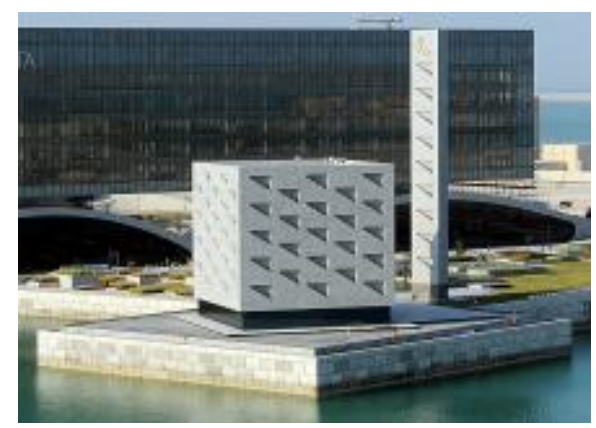

"شكل رقم ^" مسجد أركابيتا ـ البحرين

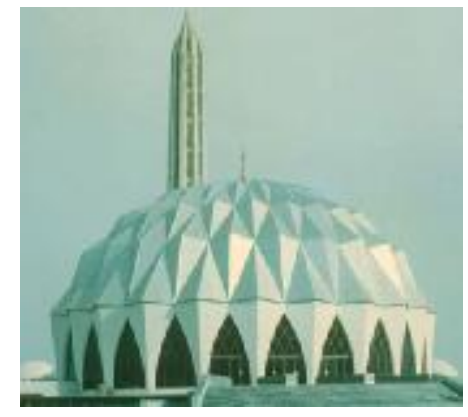

"شكل رقم V" مسجد النيلين - السودان

https://alfozanaward.org/ar/mosques/arcapita-ar/ http://earth-arch.blogspot.com/2013/11/493.html

"شكل رقم ـ ا" مسجد شرف الدين - البوسنة والهرسك

http://www.akdn.org/architecture/project/sherefudin s-white-mosque

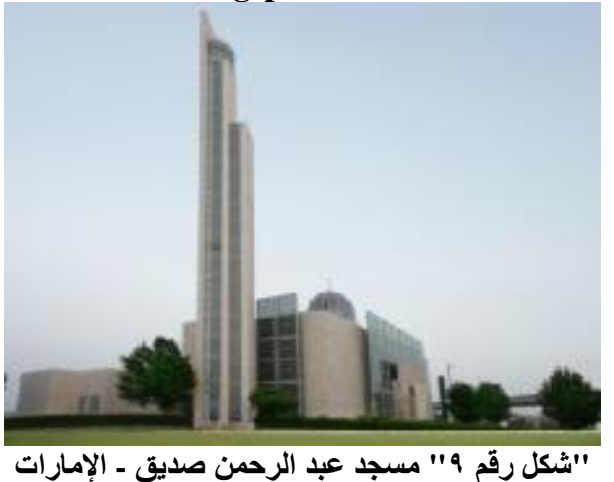

https://alfozanaward.org/ar/mosques/abdulrahma n-alsedeek-ar/

ـــ م مساجد تخلت عن العناصر الرمزية: فى محاولة للتجريد و التبسيط نجد الاختفاء الكلى للعناصر المعمارية المميزة

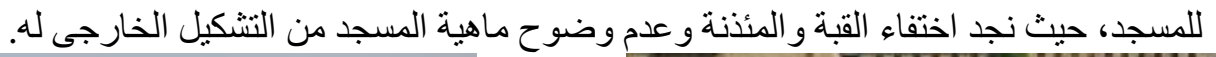

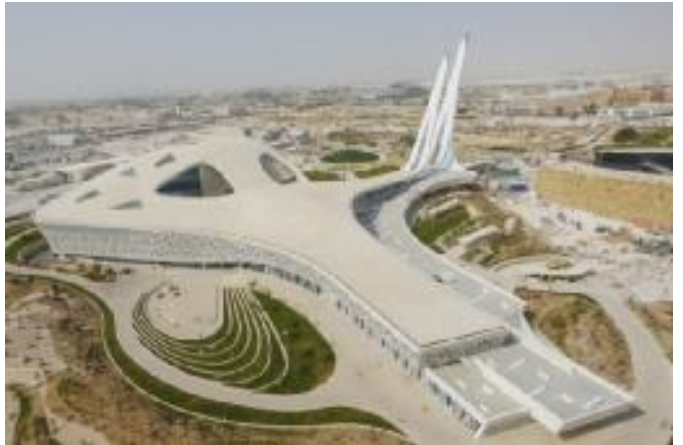

"شكل رقم r ا" ا" مسجد المدينة التعليمية ـ قطر

https://alfozanaward.org/ar/mosques/the-qatarfaculty-of-islamic-studies-qfis-ar/

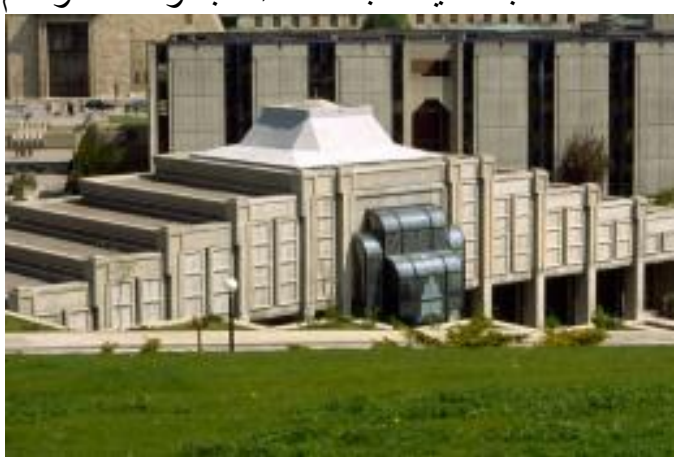

"شكل رقم ||" |" مسجد البرلمان التركى - تركيا

http://www.akdn.org/architecture/project/mosquegrand-national-assembly 


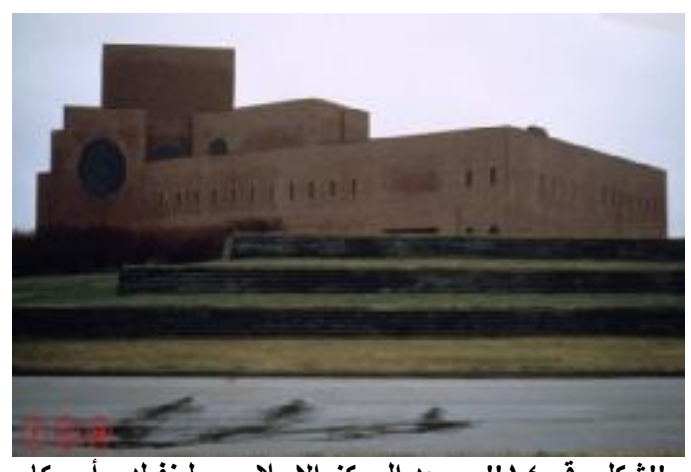

"شكل رقم ع ا" مسجد المركز الإسلامى ببلينفيلا ـ أمريكا http://www.islamicity.org/2119/mosque-design-in-theunited-states,

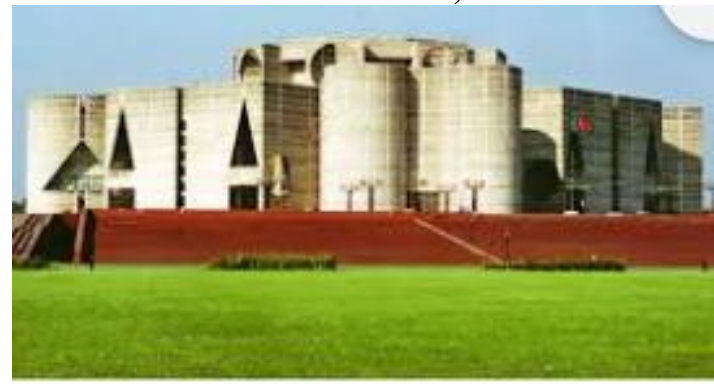

"شكل رقم 1 ا" مسجد الجمعية الوطنية ــ بنجلاديش http://archnet.org/sites/70/media_contents/9734
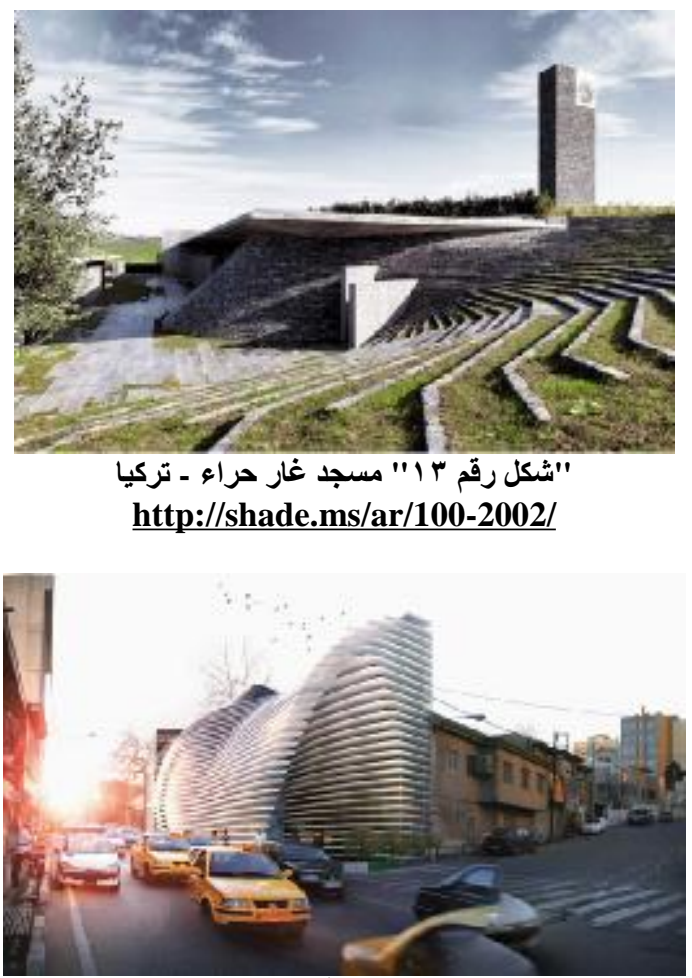

"شكل رقم 0 1" مسجد أمير المؤمنين - إيران http://www.archdaily.com/324909/mosque-amiral-momenin-proposal-caatarchitecture-studio 9- ت تأثير العناصر الرمزية في تكوين الصورة البصرية للمدينة:-

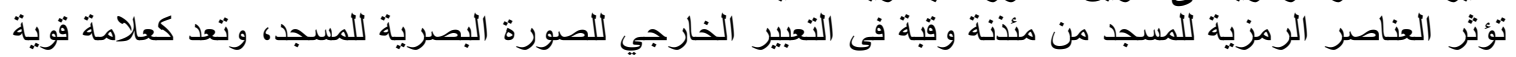

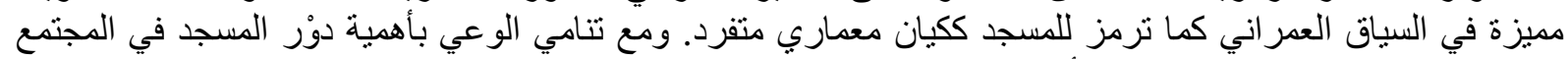

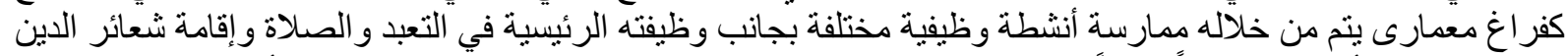

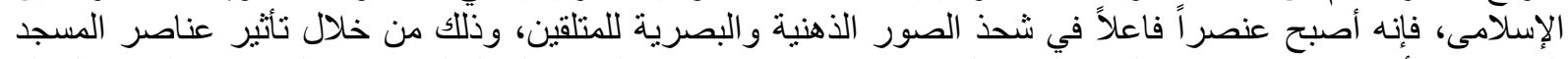

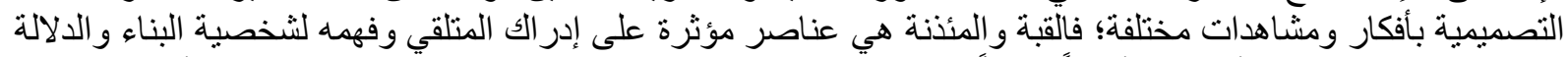

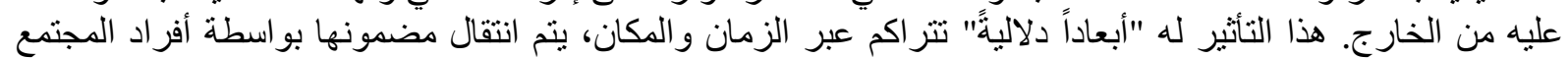

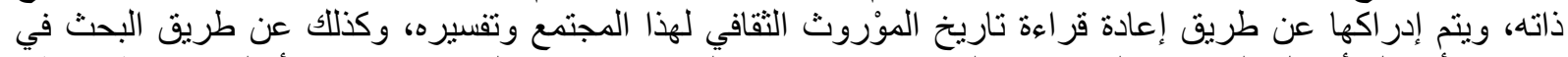

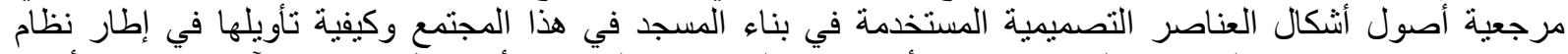

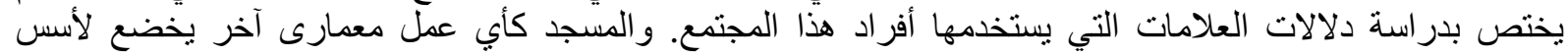

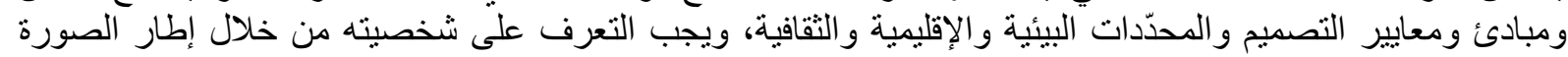
الدالة عليه.

• الدراسة أثر العناصر الرمزية فى التعرف على المسجد:-

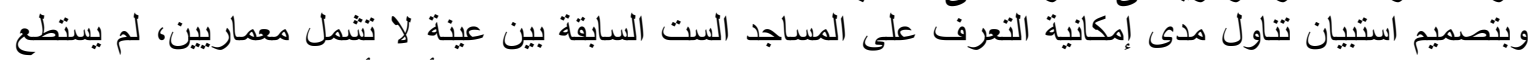

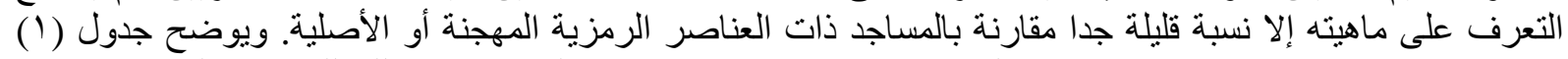

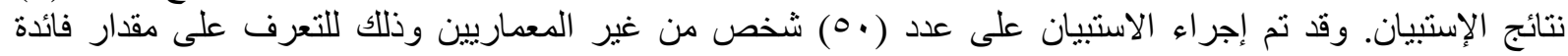
العناصر الرمزية للمساجد فى إمكانية وضوح الإنيان عاهية المبنى من عدمه. 
CLASSIFYING MOSQUES ACCORDING TO THE SYMBOLISM OF THE ARCHITECTURAL ELEMENTS AN ANALYTICAL STUDY OF A BASOUNAH MOSQUE - EGYPT

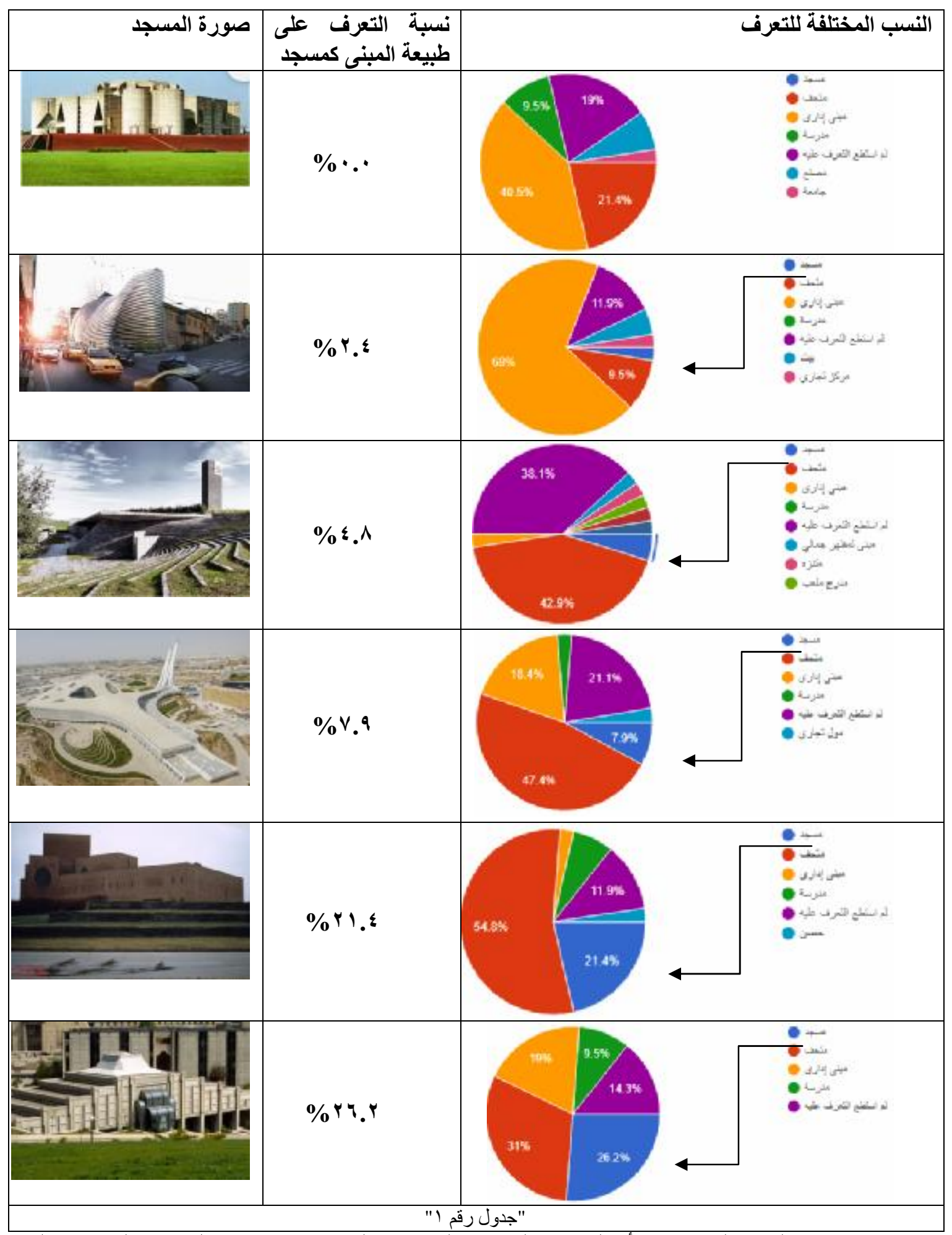

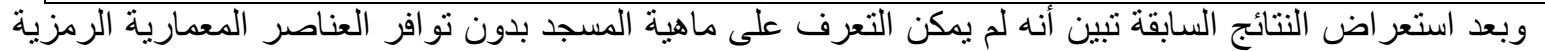

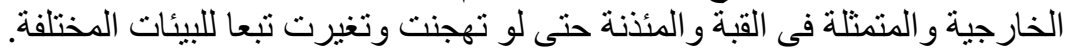

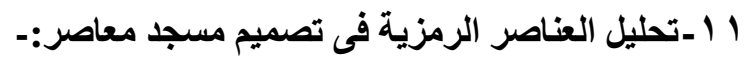

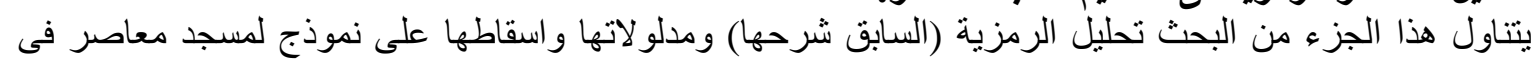

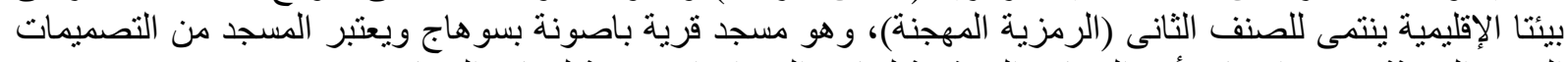

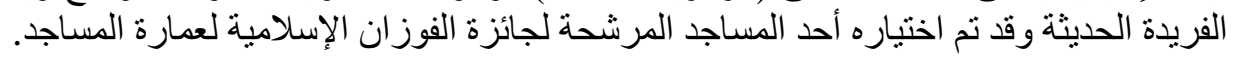




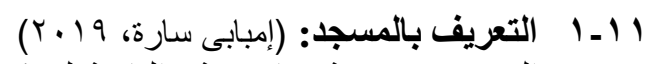

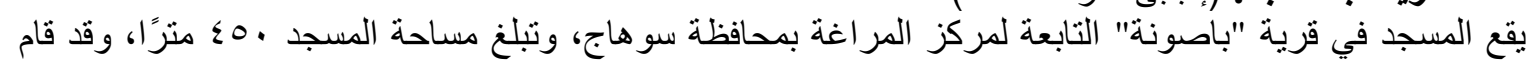

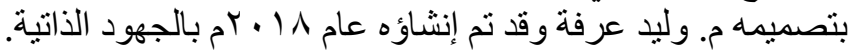

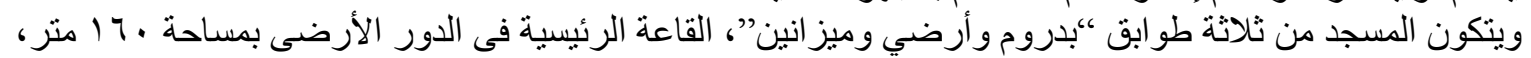

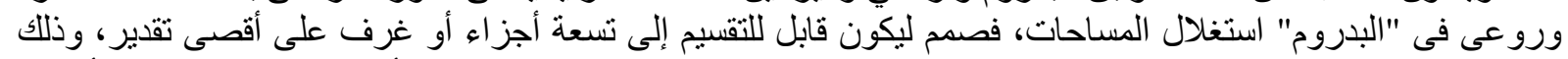

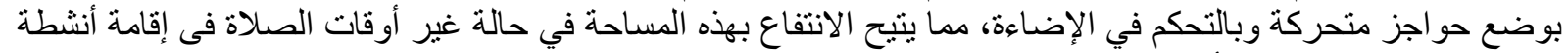

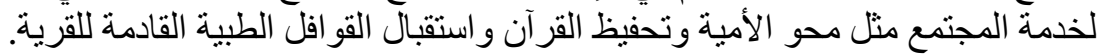

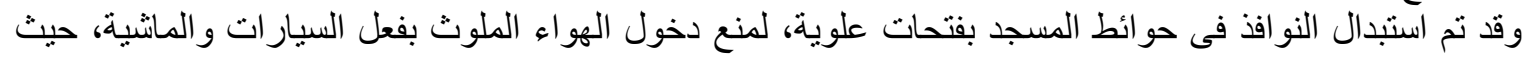

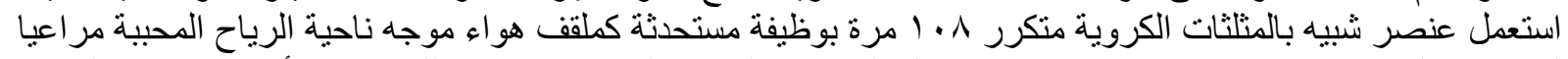

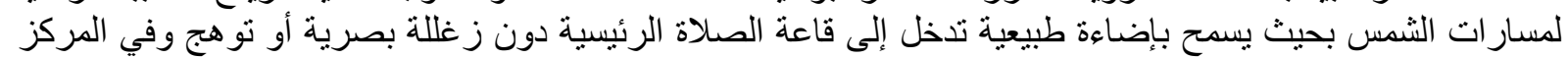

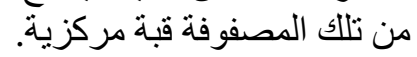

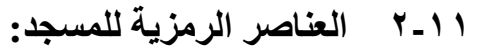

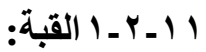
ويبلغ قطر ها آم و ارتفاعها سام، وروعى في تكوين القبة الرئيسية للمسجد النسبة الذهبية.

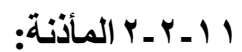

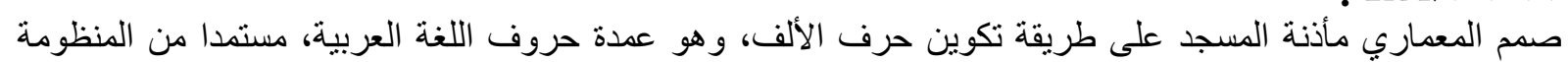

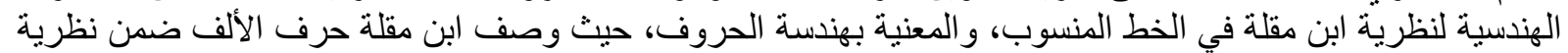

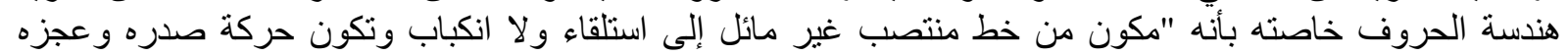

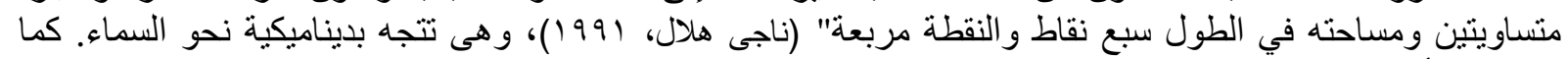

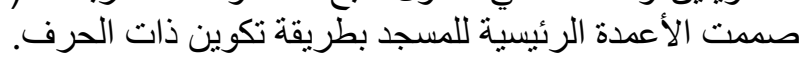

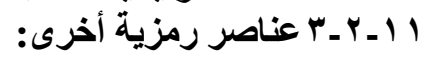

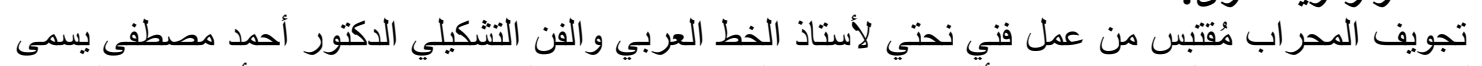

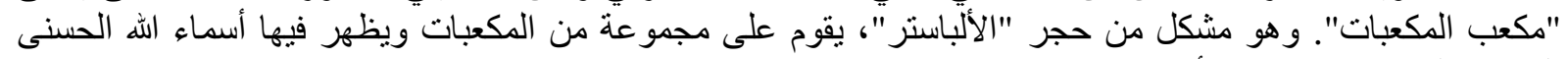

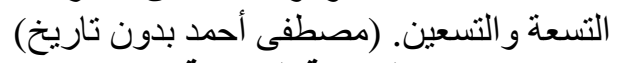

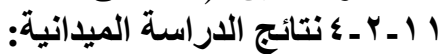

يعتبر المسجد من المساجد الرمزية المهجنة حيث استخدم المصمم مفردات وعناصر المسجد الرمزية "القبة

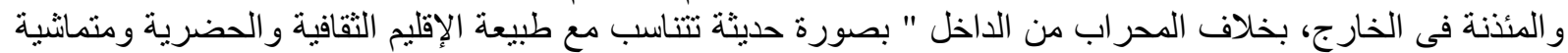

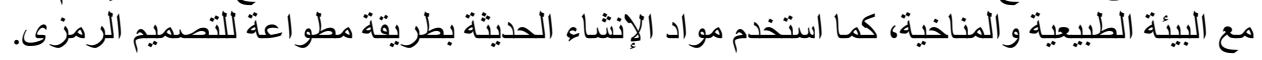

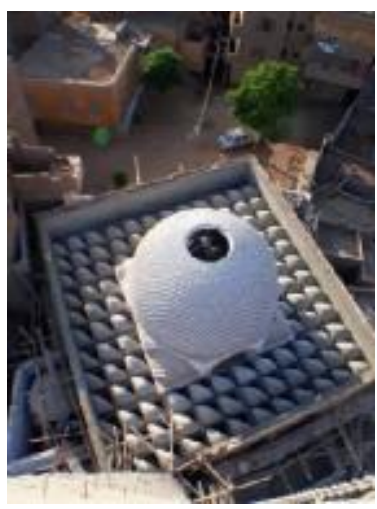

"شكل رقمج 1 " القبة والفتحات العلوية

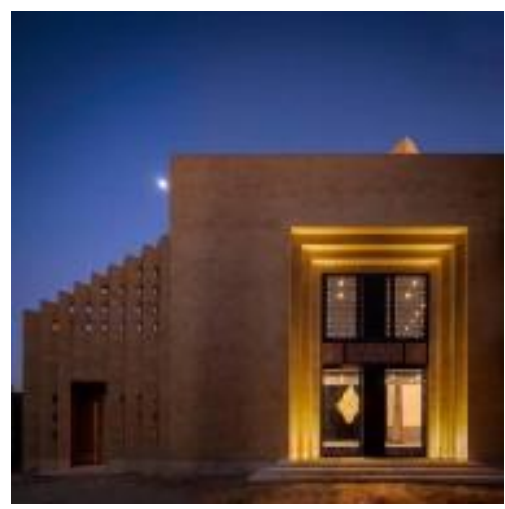

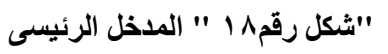

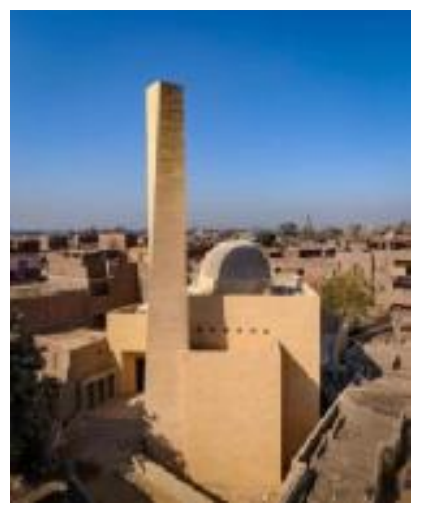

"شكل رقم V " المئنة تكوين حرف الألف 


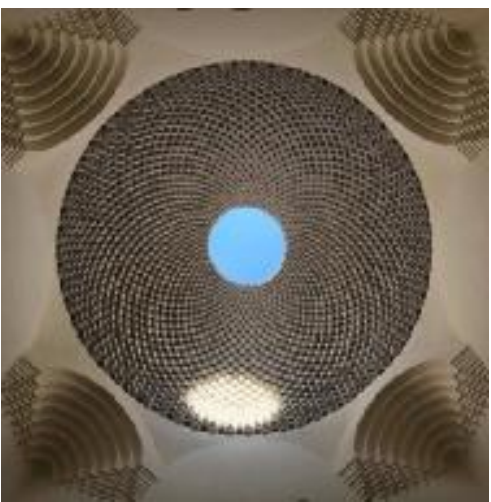

"شكل رق ץ ץ " القبة من الداخل

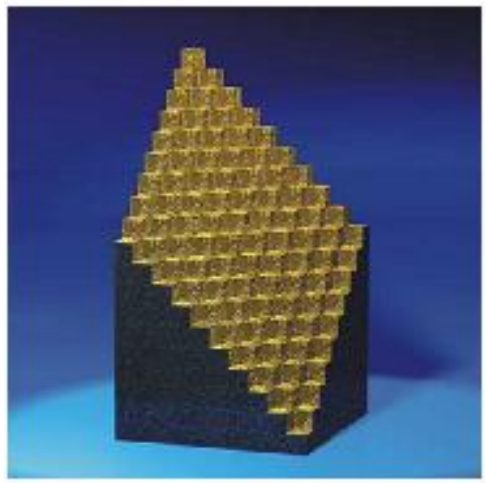

"شكل رقم ه ץ" مكعب المكعبات للقنان أحمد مصطفى

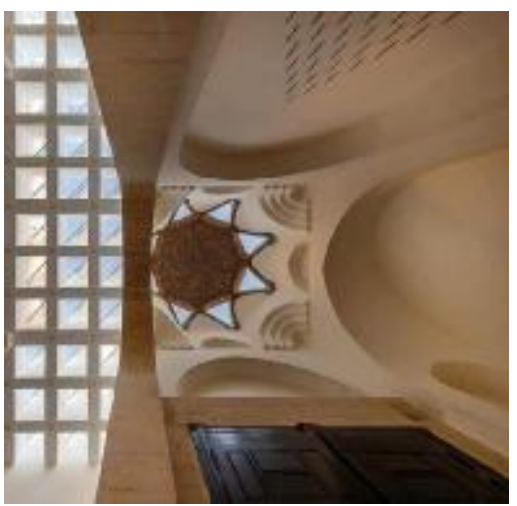

"شكل رقم اب" السقف من الداخل

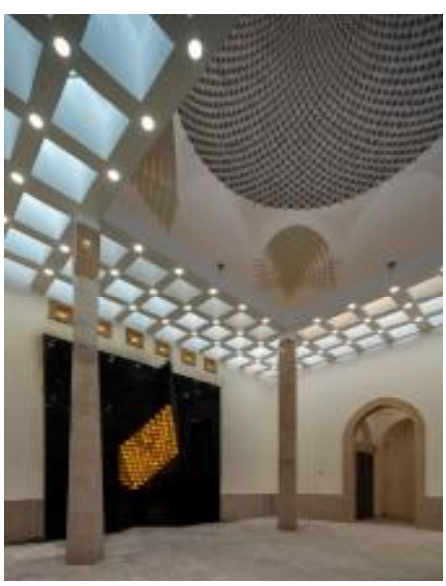

" - مكل رقم ع ץ" المحراب

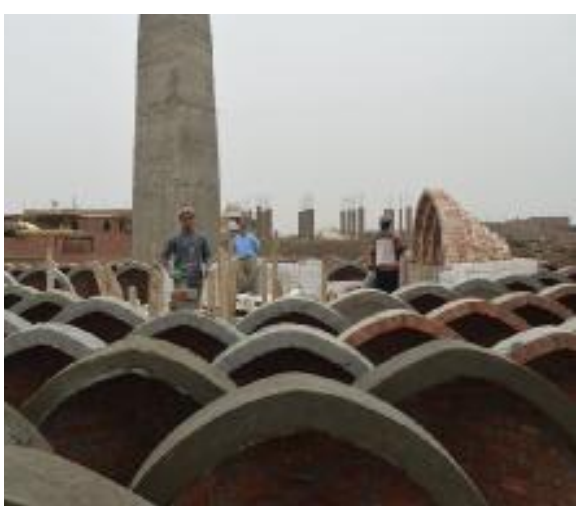

"شكل رقم • ץ" الفتحات العلوية

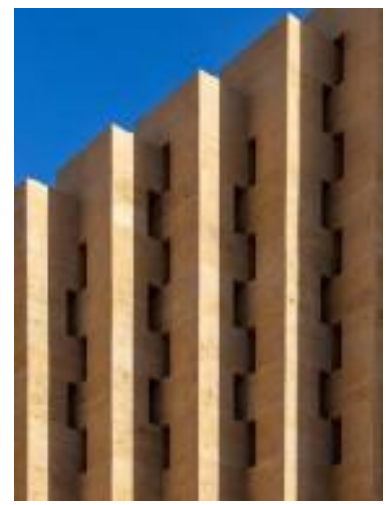

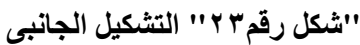

جمبع الأشكال لمسجد باصونة "دراسة الحالة"

(1) (1) عنصرى المئذنة والقبة من أهم العناصر الرمزية فى عمارة المسجد.

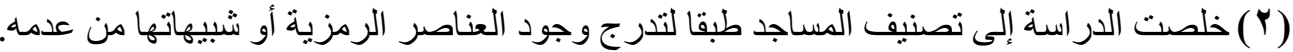

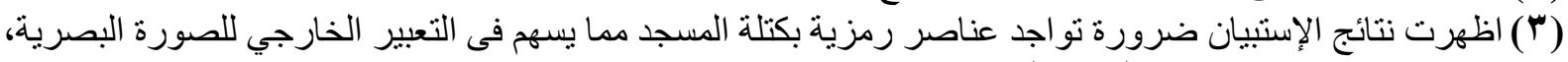

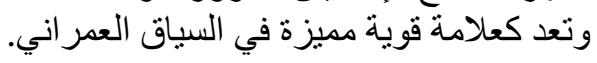

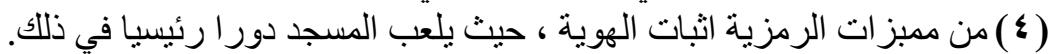

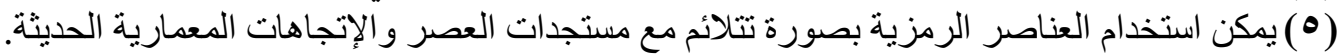

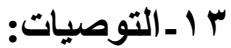

(1) (1) (1) (1) الاسفرة تضمين المساجد عناصر رمزية سواء كانت متفقة مع العناصر المتوارثة أو عناصر مستحدثة.

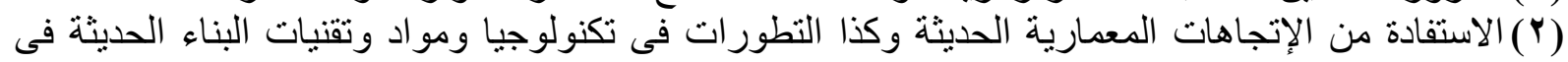

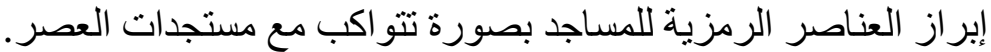

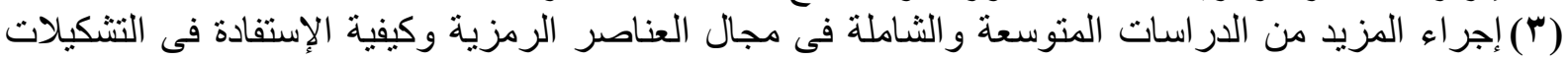
الحديثة للمساجد، خصوصا فى الدول ذات الأقليات الإسلامية التى تواجه صعوبات حالية فى الأشكال المعمارية للمساجد.

(ع) يوصى البحث بأن يُطبق هذا التصنيف المقترح فى مقررات التاريخ الإسلامى لأقسام العمارة بالجامعات

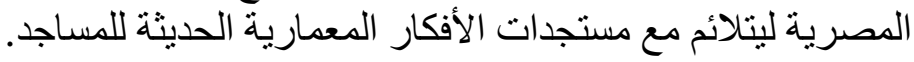


CLASSIFYING MOSQUES ACCORDING TO THE SYMBOLISM OF THE ARCHITECTURAL ELEMENTS AN ANALYTICAL STUDY OF A BASOUNAH MOSQUE - EGYPT

بو ابة جريدة الأهر ام على الإنترنت.

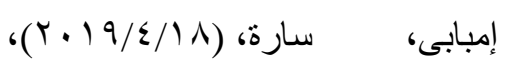

http://gate.ahram.org.eg/News/2144873.aspX

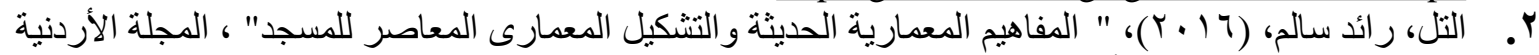

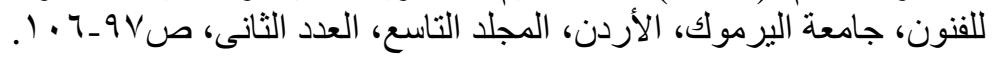

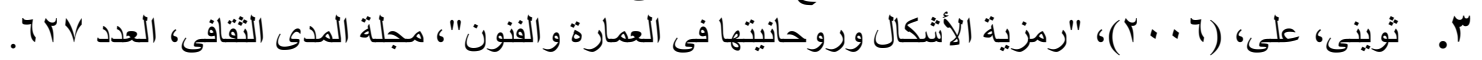

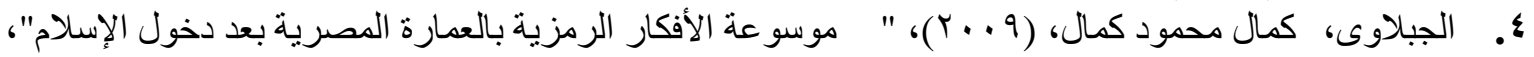

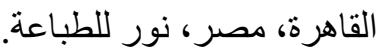

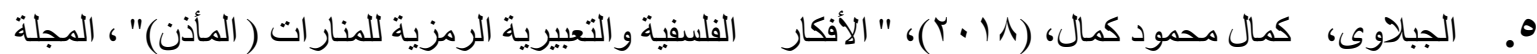

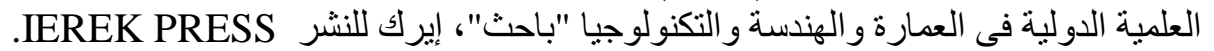

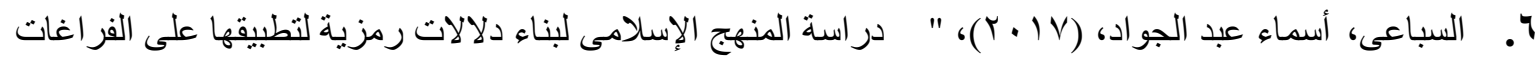

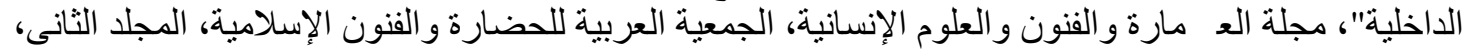

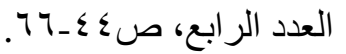

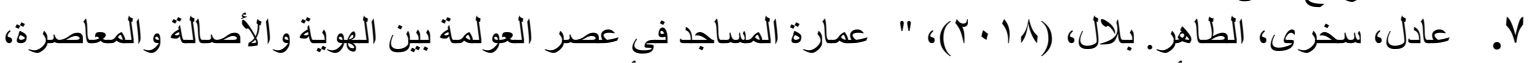

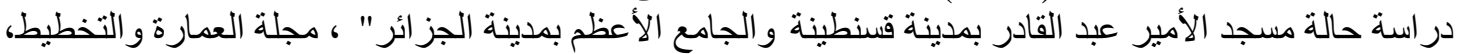

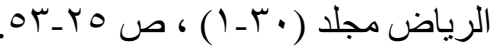

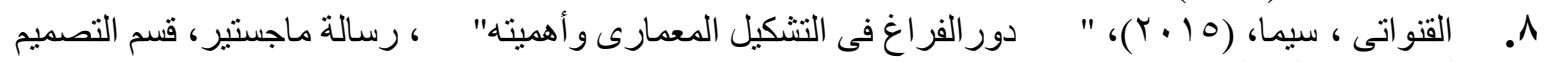

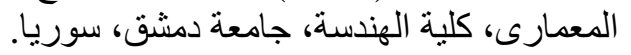

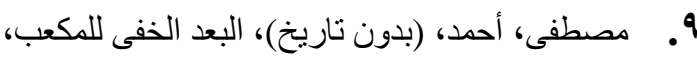
http://www.thecubeofcubes.com/cube/the_cube_arb.html • 1 ـ ناجى ،هلال، (199 (19) ) ابن مقلة خطاطا وأديبا و إنسانا مع تحقيق رسالته فى الخطو القلم" ، بغداد، العر اق، دار الثئون الثقافية العامة. 